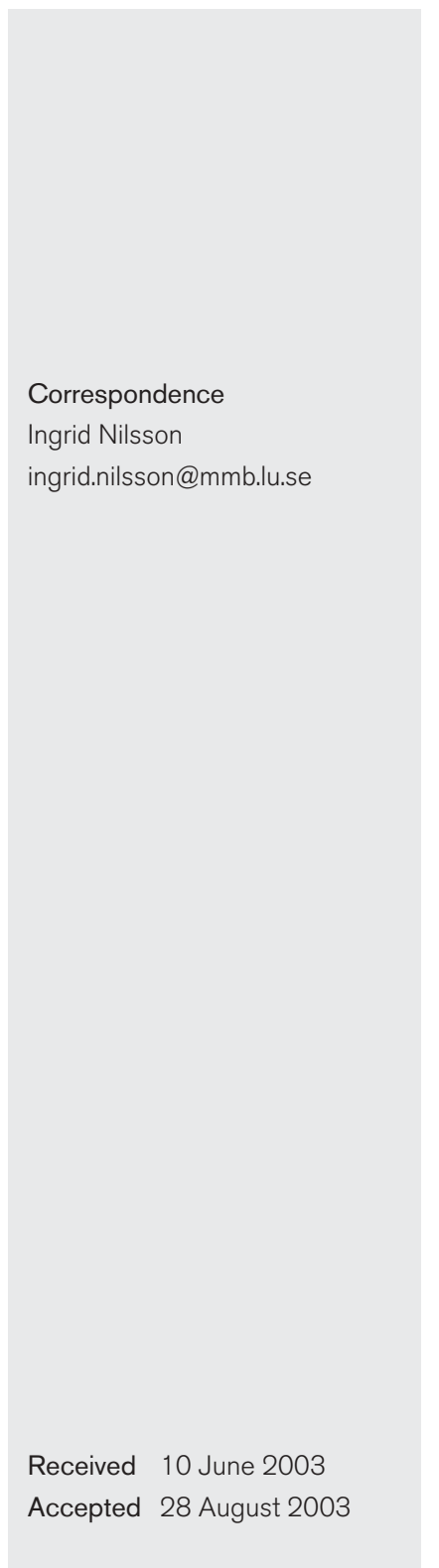

\section{Increased prevalence of seropositivity for non-gastric Helicobacter species in patients with autoimmune liver disease}

\author{
Ingrid Nilsson, ${ }^{1}$ Iryna Kornilovs'ka, ${ }^{1}$ Stefan Lindgren, ${ }^{2}$ Åsa Ljungh ${ }^{1}$ \\ and Torkel Wadström ${ }^{1}$ \\ ${ }^{1}$ Department of Medical Microbiology, Dermatology and Infection, Division of Bacteriology, Lund \\ University, Sölvegatan 23, S-223 62, Lund, Sweden \\ ${ }^{2}$ Gastroenterology-Hepatology Division, Department of Medicine, University Hospital of Malmö, \\ Sweden
}

\begin{abstract}
Various Helicobacter species have been isolated from the stomach, intestinal tract and liver of a variety of mammalian and some avian species, and Helicobacter DNA has been detected in human bile and liver samples. An immunoblot assay was established to analyse serum antibody responses to non-gastric Helicobacter species in patients with autoimmune liver diseases, in comparison with healthy individuals. Sera from 36 patients with primary sclerosing cholangitis (PSC), 21 with primary biliary cirrhosis, 19 with autoimmune chronic hepatitis and 80 blood donors were analysed by immunoblot, using cell-surface proteins from Helicobacter pullorum, Helicobacter bilis and Helicobacter hepaticus as antigens. Prior to testing, sera were cross-absorbed with a whole-cell lysate of Helicobacter pylori. Antibody reactivity to various proteins of these three Helicobacter species was measured by densitometric scanning and results were processed by computer software to estimate antigenic specificity. Results were also compared with antibody response to $H$. pylori. For $H$. pullorum, reactivity to at least two of the proteins with molecular masses of 48, 45, 37, 20 and $16 \mathrm{kDa}$, for $H$. hepaticus, reactivity to the 76,30 and $21 \mathrm{kDa}$ proteins and for $H$. bilis, reactivity to the 22 and $20 \mathrm{kDa}$ proteins, seemed to have high specificity. Positive immunoblot results with sera from patients with PSC to antigens of $H$. pullorum, $H$. bilis and $H$. hepaticus were found in 38,22 and $25 \%$ of cases, respectively, and from patients with other autoimmune liver diseases, in 30, 22 and $22 \%$ of cases, respectively. Prevalence of serum antibodies to non-gastric Helicobacter species was significantly higher in patients with autoimmune chronic liver diseases than in healthy blood donors $(P<0.001)$. Increased antibody levels to enterohepatic Helicobacter species raise questions concerning an infectious role of these emerging bacterial pathogens in human autoimmune liver diseases.
\end{abstract}

\section{INTRODUCTION}

Genetic, environmental and microbial factors are believed to play a role in the development of chronic liver diseases of presumed autoimmune aetiology, such as primary sclerosing cholangitis (PSC) and primary biliary cirrhosis (PBC). Unknown environmental factors or infectious agents could trigger an immunological reaction and an inflammatory response that result in the destruction of intra- and extrahepatic bile ducts (Lee \& Kaplan, 1995; Sutton \& Neuberger, 2002). No causative microbial agent has been defined clearly for humans. Normal intestinal microflora or previously unrecognized intestinal pathogens might contribute to the

Abbreviations: EIA, enzyme immunoassay; PBC, primary biliary cirrhosis; PSC, primary sclerosing cholangitis. development of disease in susceptible hosts. More recently, DNA of different Helicobacter species was detected in human bile and gall-bladder samples, suggesting that these organisms may colonize or translocate to the biliary tract of humans and may be associated with hepatobiliary diseases (Fox et al., 1998, 2001; Leong \& Sung, 2002; Ljungh \& Wadström, 2002).

Isolation of a Helicobacter species from a human liver was reported recently (de Magalhaes Queiroz \& Santos, 2001). We observed that PSC and PBC patients were positive for Helicobacter spp. in liver biopsies by PCR and DNA sequence analysis and visualized Helicobacter in Kupffer cells by immunohistochemistry (Nilsson et al., 2000a; Wadström et al., 2001). Similar findings were reported for patients with cholangio- and hepatocellular carcinoma (Nilsson et al., 
2001). Furthermore, a significant difference in antibody response was found in patients with chronic liver disease compared to blood donors (Ananieva et al., 2002).

Helicobacter and human heat-shock protein 70 (Hsp70) share cross-reactive epitopes, suggesting a possible autoimmune role in disease pathogenesis (Ward et al., 1996). High antibody reactivity to these proteins was also found in sera of alcoholic patients with chronic liver disease (Nilsson et al., 2000b).

The aim of the present study was to analyse immune responses to cell-surface proteins of Helicobacter pullorum, Helicobacter bilis and Helicobacter hepaticus, in order to explore the possible role of these related emerging pathogens in human autoimmune liver diseases.

\section{METHODS}

Patient samples. Serum samples from patients (aged 31-88 years) with PSC $(n=36), \operatorname{PBC}(n=21)$ or autoimmune hepatitis $(n=19)$ were analysed. Sera were collected from a prospective series of patients investigated at the Department of Medicine, University Hospital of Malmö, for suspected chronic liver disease due to elevated concentrations of liver enzymes and/or clinical symptoms of $>6$ months duration. Patients with PBC were all women and all had a cholestatic biochemical profile with a positive test for anti-mitochondrial antibodies, elevated plasma concentrations of IgM and a liver biopsy that was compatible with the diagnosis. Among the patients with PSC, 15 were women. The diagnosis of PSC was verified in each case by endoscopic retrograde cholangiography. Among the patients with autoimmune chronic hepatitis, 16 were women. These patients all had anti-nuclear antibodies and smooth muscle antibodies, as well as increased plasma concentrations of IgG and liver biopsies that were compatible with the diagnosis. All patient sera were negative for hepatitis C virus (RIBA3) and hepatitis B surface antigen (ELISA) (Verbaan et al., 1998). Blood donor serum samples $(n=80)$, collected randomly at the blood-transfusion unit at the University Hospital of Malmö, were included to represent a healthy population without any gastrointestinal or liver diseases for comparison of antibody reactivity to antigens of Helicobacter species. All serum samples were kept frozen at $-20{ }^{\circ} \mathrm{C}$ until they were analysed.

Bacterial strains and antigen preparations. A human isolate of $H$. pullorum (strain CCUG 33838; Cell Culture Collection, University of Gothenburg), H. bilis strain CCUG $38995^{\mathrm{T}}$ and H. hepaticus strain CCUG $33637^{\mathrm{T}}$ (murine isolates) were cultured on Brucella blood agar as described previously (Kornilovs'ka et al., 2002) for 4 days at $37^{\circ} \mathrm{C}$ in a microaerobic atmosphere (Anoxomat; MART Microbiology). Helicobacter pylori strain CCUG $17874^{\mathrm{T}}$ was cultured (low passage; fewer than four times) on GAB-CAMP agar (Soltesz et al., 1992) without antibiotics for 3 days at $37^{\circ} \mathrm{C}$ in a microaerobic atmosphere (Anoxomat; MART Microbiology).

Acid/glycine extraction of cell-surface proteins of $H$. bilis, $H$. hepaticus and $H$. pylori was performed as described previously (Lelwala-Guruge $e t$ al., 1992). This method did not efficiently release cell-surface proteins from $H$. pullorum; therefore, a water-washing procedure was used for this bacterium (Kornilovs'ka et al., 2002). Protein concentrations of the extracts were determined by the Bradford method, using the Bio-Rad protein assay and BSA (Bio-Rad) as standard.

SDS-PAGE and immunoblot assay. SDS-PAGE was performed under reducing conditions (Laemmli, 1970) by using Criterion cell electrophoresis equipment (Bio-Rad). Extracted Helicobacter proteins were separated in a $10-20 \%$ gradient gel with a $5 \%$ stacking gel (Criterion pre-cast gels; Bio-Rad) (Kornilovs'ka et al., 2002). Separated Helicobacter proteins were transferred electrophoretically to a polyvinylidene difluoride membrane as reported previously (Nilsson et al., 1997). For each immunoblot assay, a polyclonal rabbit antiserum to each of the four Helicobacter species was included as calibrator (Kornilovs'ka et al., 2002). Protein bands obtained by immunoblot (after the absorption step described below) were scanned by using a GS710 Imaging densitometer and compared and processed by Quantity One software (both from Bio-Rad). For H. pullorum, reactivity to at least two of the proteins with molecular masses of $48,45,37,20$ and $16 \mathrm{kDa}$, for $H$. hepaticus, reactivity to the 76,30 and $21 \mathrm{kDa}$ proteins and for $H$. bilis, reactivity to the 20 and $22 \mathrm{kDa}$ proteins, seemed to have high specificity. Criteria for an $\mathrm{H}$. pylori-positive immunoblot were followed as described previously (Nilsson et al., 1997).

Immunoabsorption experiments. To remove potentially crossreacting antibodies between $H$. pylori and the other three Helicobacter species, a whole-cell lysate of $H$. pylori (CCUG $17874^{\mathrm{T}}$ ) was used. Ten microlitres of serum was added to $1 \mathrm{ml}$ sonicated cells $\left(A_{540}, 1 \cdot 5\right)$ and incubated for $16 \mathrm{~h}$ at $8{ }^{\circ} \mathrm{C}$ under constant shaking. Cells were removed by centrifugation at $12000 \mathrm{~g}$ for $15 \mathrm{~min}$ and supernatants were used for the immunoblot assay. As a control for complete absorption of $H$. pylori antibodies, an $H$. pylori enzyme immunoassay (EIA) was performed as described previously (Ananieva et al., 2002).

Polyclonal rabbit antisera to the Helicobacter species (Kornilovs'ka et al., 2002) were used for extended absorption experiments. In addition, cross-reactivity was analysed by a dot-blot assay. Antisera were absorbed step-wise as described above, with whole cells of: (i) H. pylori + Escherichia coli (ATCC 25922); (ii) H. pylori + E. coli + Lactobacillus paracasei (Ljungh et al., 2002); and (iii) H. pylori + E. coli + L. paracasei + Campylobacter jejuni $\left(\operatorname{ATCC} 33560^{\mathrm{T}}\right)$. Membrane strips were coated with antigens of the above bacteria and with antigens of 'Flexispira rappini' (CCUG 23435), Helicobacter canis (CCUG 33835), $H$. pullorum, $H$. bilis and $H$. hepaticus (10 $\mu \mathrm{g}$ per dot) and probed with the polyclonal non-absorbed and absorbed rabbit antisera (diluted $1: 200$ ). Dots were visualized by using the same buffer as described for the immunoblot assay. After an initial absorption step with $H$. pylori antigens only, any additional absorption steps did not affect the test results with patient sera.

Statistics. Statistical analysis included descriptive statistics for each group; significant differences between the patient groups and healthy blood donors were calculated by the non-parametric F-test.

\section{RESULTS}

To illustrate differences in antibody levels before and after absorption, a densitogram of three scanned immunoblot strips that contained separated proteins of the non-gastric Helicobacter species and was probed with a patient serum (strongly reactive before absorption) was prepared (Fig. 1). Each peak corresponds to one band on the immunoblot strip and height corresponds to its density. With this patient's serum, almost all reactivity to $H$. bilis disappeared, whereas the serum seems to contain antibodies specific to $H$. hepaticus.

In the dot-blot assay with antisera raised against antigens of $H$. pullorum, H. bilis and H. hepaticus, a high degree of crossreactivity was demonstrated, which was reduced significantly by using the preabsorption step. Reactivity to proteins of 'F. rappini' remained and a weak response to proteins of 


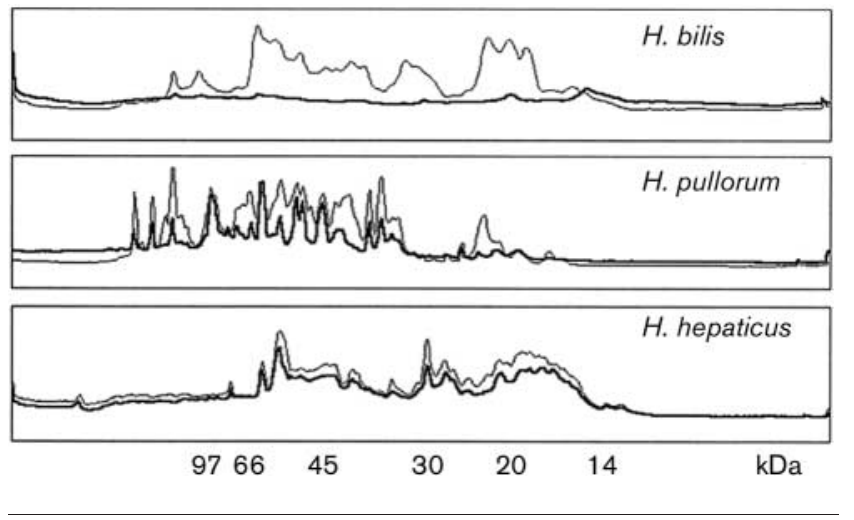

Fig. 1. To illustrate differences in the antibody response before and after absorption, a densitogram of three scanned immunoblot strips was prepared, each containing equal amounts of separated proteins of non-gastric Helicobacter species, and probed with a patient serum diluted 1:100 (strongly reactive before absorption). Each peak corresponds to one band on the immunoblot strip and the height corresponds to its density. With this serum, almost all reactivity to $H$. bilis disappeared, whereas this patient's serum seems to contain antibodies specific to $H$. hepaticus. Thin line, non-absorbed serum; thick line, absorbed serum.

$H$. canis was also noted. Cross-reactivity with proteins of $C$. jejuni, L. paracasei, E. coli, H. pullorum, H. bilis, H. hepaticus and $H$. pylori disappeared after the absorption step.

None of the preabsorbed blood donor sera reacted with any of the 48, 45, 37, 20 or $16 \mathrm{kDa}$ proteins of $H$. pullorum, whilst one of 80 sera $(1 \%)$ was positive for the $H$. bilis proteins $(20$ and $22 \mathrm{kDa}$ ). To the $H$. hepaticus proteins $(76,30$ and 21 $\mathrm{kDa})$, three of $80(4 \%)$, and to H. pylori, 13 of 80 (16\%), sera were positive (Table 1).

Sera from PSC patients contained antibodies to at least two of the specific $H$. pullorum proteins in 14 of 36 (38\%), to $H$. bilis in eight of $36(22 \%)$ and to H. hepaticus in nine of $36(25 \%)$, respectively. Results obtained by immunoblot in the group of PSC patients were statistically significant, compared to the immunoblot results of donor sera $(P<0.05, P<0.001$ and $P<0.001$, respectively). Among sera from patients with autoimmune liver diseases other than PSC, 12 of $40(30 \%)$ were positive by $H$. pullorum immunoblot, nine of $40(22 \%)$ were positive by immunoblot to $H$. bilis and five of $40(12 \%)$ were positive by immunoblot to $H$. hepaticus. These results differed significantly from those of blood donors $(P<0.001$ for the three species) (Table 1). A positive $H$. pylori immunoblot was found in eight of 36 (22\%) of the PSC sera and in 23 of $40(57 \%)$ of sera from patients with other autoimmune disorders (Table 1).

\section{DISCUSSION}

Enteric, bile-tolerant Helicobacter species, such as H. pullorum, $H$. bilis and $H$. hepaticus, are fastidious microaerophilic microbes that are extremely difficult to isolate from stool samples and other clinical specimens. They are probably inhibited by other microbes in complex test samples, as well as by certain bile and intestinal metabolites. In this study, we aimed to develop and optimize antibody-based detection tests, analogous with some other fastidious bacterial pathogens that are difficult to isolate, e.g. Leptospira, Treponema, Borrelia, Ehrlichia and various Rickettsia species. Furthermore, difficulty in obtaining human liver, gall-bladder and bile samples for PCR diagnosis should stimulate the development of immuno-based assays to detect infections with these new enteric pathogens.

The absorption procedure to remove possible cross-reacting H. pylori antibodies should rule out the risk that infection with this pathogen would give a false-positive result in the immunoblot, not excluding cross-reactivity between various enterohepatic Helicobacter species. Cross-reactivity to proteins of ' $F$. rappini' was observed in the dot-blot assay, most probably resulting from homology between heat-shock proteins of various Helicobacter species. However, weak reactivity to $H$. canis was also found; this species has not so far been found in human liver or bile samples. Much less or no cross-reactivity was observed to proteins of C. jejuni, L.

Table 1. Immunoblot results of sera from patients with autoimmune liver diseases and healthy individuals

Sera were absorbed with sonicated cells of $H$. pylori prior to testing for antibody reactivity to antigens of $H$. pullorum, $H$. bilis and $H$. hepaticus.

\begin{tabular}{|lccc|}
\hline Antigens from: & \multicolumn{3}{c|}{ No. positive sera (\%) } \\
\cline { 2 - 4 } & PSC $(\boldsymbol{n}=\mathbf{3 6})$ & $\begin{array}{c}\text { Other autoimmune } \\
\text { diseases }(\boldsymbol{n}=\mathbf{4 0})\end{array}$ & $\begin{array}{c}\text { Blood donors } \\
(\boldsymbol{n}=\mathbf{8 0})\end{array}$ \\
\hline H. pullorum & $14(38)^{*}$ & $12(30)^{*}$ & $0(0)$ \\
H. bilis & $8(22)^{*}$ & $9(22)^{*}$ & $1(1)$ \\
H. hepaticus & $9(25)^{*}$ & $5(12)^{*}$ & $3(4)$ \\
H. pylori & $8(22)$ & $23(57)$ & $13(16)$ \\
\hline
\end{tabular}

*Significant difference compared to blood donors $(P<0 \cdot 001)$. 
paracasei and E. coli. Immunoblot bands, following crossabsorption of the tested patient samples, could thus be interpreted as specific.

Very few of the blood donors demonstrated seropositivity for antigens from non-gastric Helicobacter species, in agreement with a previous EIA study on Estonian blood donor sera (Ananieva et al., 2002).

Antibody reactivity to $H$. pullorum and $H$. bilis was similar with sera from patients with PSC and autoimmune chronic hepatitis, in contrast to the seroreactivity to proteins of $H$. hepaticus, where PSC sera showed a higher antibody response ( $25 \%)$ than those of autoimmune hepatitis patients (12\%). The significance of this finding requires further studies. The $H$. pylori immunoblot showed that the antibody response among PSC patients was lower than that of autoimmune hepatitis patients, with 22 and $57 \%$ positive tests, respectively. Similar results were obtained by EIA in a previous investigation (Nilsson et al., 2000b), which also included sera from patients with alcoholic liver disease that showed a strong antibody response to Helicobacter heat-shock proteins.

To purify highly specific immunogenic proteins as diagnostic antigens for optimized immunoassays for these emerging Helicobacter species would be of great advantage. Detection of antibodies to non-gastric, enteric Helicobacter species provides, however, only indirect evidence of infection; immunohistochemical staining methods should be developed in parallel, as culture of non-gastric Helicobacter species from various clinical specimens continues to be a major problem that limits studies of their prevalence and role in hepatic diseases.

In the first human study published in this field, DNA of $H$. bilis and $H$. pullorum was commonly identified by PCR in Chilean patients with chronic cholecystitis (Fox et al., 1998). The isolation of a Helicobacter strain from a human liver (de Magalhaes Queiroz \& Santos, 2001) and detection of Helicobacter DNA by PCR in bile from patients with bile-duct diseases (Roe et al., 1999; Matsukura et al., 2002) suggest that further systematic studies should be carried out in patients with liver and bile-duct diseases. Interestingly, Avenaud et al. (2000) detected Helicobacter species in hepatocellular carcinoma and cholangiocarcinoma, and Nilsson et al. (2002) detected Helicobacter species in patients with pancreatic cancer. These and other gastric bile-sensitive species have been proposed to translocate to the bile tract and liver by using macrophages to carry bacteria from the gut to the mesenteric lymph nodes, to enter the blood stream and seed other sites, e.g. in individuals with poor liver function (Garcia-Tsao, 2001).

Autoimmune diseases are conditions in which the immune system damages normal tissue components of the individual. In patients with autoimmune hepatitis and $\mathrm{PBC}$, significant titres of anti-nuclear and anti-smooth muscle autoantibodies are commonly observed (Alvarez et al., 1999). Chronic viral infections play a crucial role in the initiation and main- tenance of pathological processes in the liver (Haydon \& Neuberger, 2000), but little is known about other microbial pathogens that cause chronic infections, which may trigger an autoimmune response. Animal models to study Helicobacter spp. infections should be developed to analyse their relation to autoimmune liver diseases, as well as further attempts to culture microbes from liver specimens.

This study will hopefully stimulate more studies to explore the possible role of enteric bile-tolerant and -sensitive Helicobacter species in the pathogenesis of hepatobiliary disease in humans.

\section{ACKNOWLEDGEMENTS}

This study was supported by grants from the Swedish Research Council (16x04723 and 6x11229), Region Scania (ALF), the Medical Faculty at Lund University and the Forssman Foundation of the Royal Physiographic Society in Lund.

\section{REFERENCES}

Alvarez, F., Berg, P. A., Bianchi, F. B. \& 39 other authors (1999). International Autoimmune Hepatitis Group Report: review of criteria for diagnosis of autoimmune hepatitis. J Hepatol 31, 929-938.

Ananieva, O., Nilsson, I., Vorobjova, T., Uibo, R. \& Wadström, T. (2002). Immune responses to bile-tolerant Helicobacter species in patients with chronic liver diseases, a randomized population group, and healthy blood donors. Clin Diagn Lab Immunol 9, 1160-1164.

Avenaud, P., Marais, A., Monteiro, L., Le Bail, B., Bioulac Sage, P., Balabaud, C. \& Mégraud, F. (2000). Detection of Helicobacter species in the liver of patients with and without primary liver carcinoma. Cancer 89, 1431-1439.

de Magalhaes Queiroz, D. M. \& Santos, A. (2001). Isolation of a Helicobacter strain from the human liver. Gastroenterology 121, 1023-1024.

Fox, J. G., Dewhirst, F. E., Shen, Z. \& 8 other authors (1998). Hepatic Helicobacter species identified in bile and gallbladder tissue from Chileans with chronic cholecystitis. Gastroenterology 114, 755-763.

Fox, J. G., Schauer, D. B. \& Wadström, T. (2001). Enterohepatic Helicobacter species. Curr Opin Gastroenterol 17 (Suppl. 1), S28-S31.

Garcia-Tsao, G. (2001). Bacterial translocation: cause or consequence of decompensation in cirrhosis? J Hepatol 34, 150-155.

Haydon, G. H. \& Neuberger, J. (2000). PBC: an infectious disease? Gut 47, 586-588.

Kornilovs'ka, I., Nilsson, I., Utt, M., Ljungh, Å. \& Wadström, T. (2002). Immunogenic proteins of Helicobacter pullorum, Helicobacter bilis and Helicobacter hepaticus identified by two-dimensional gel electrophoresis and immunoblotting. Proteomics 2, 775-783.

Laemmli, U. K. (1970). Cleavage of structural proteins during the assembly of the head of bacteriophage T4. Nature 227, 680-685.

Lee, Y.-M. \& Kaplan, M. M. (1995). Primary sclerosing cholangitis. $N$ Engl J Med 332, 924-933.

Lelwala-Guruge, J., Nilsson, I., Ljungh, Å. \& Wadström, T. (1992). Cell surface proteins of Helicobacter pylori as antigens in an ELISA and a comparison with three commercial ELISA. Scand J Infect Dis 24, 457-465.

Leong, R. W. L. \& Sung, J. J. Y. (2002). Helicobacter species and hepatobiliary diseases. Aliment Pharmacol Ther 16, 1037-1045.

Ljungh, Å. \& Wadström, T. (2002). The role of microorganisms in biliary tract disease. Curr Gastroenterol Rep 4, 167-171. 
Ljungh, Å., Lan, J. \& Yanagisawa, N. (2002). Isolation, selection and characteristics of Lactobacillus paracasei subsp. paracasei F19. Microb Ecol Health Dis 14 (Suppl. 3), 4-6.

Matsukura, N., Yokomuro, S., Yamada, S., Tajiri, T., Sundo, T., Hadama, T., Kamiya, S., Naito, Z. \& Fox, J. G. (2002). Association between Helicobacter bilis in bile and biliary tract malignancies: $H$. bilis in bile from Japanese and Thai patients with benign and malignant diseases in the biliary tract. Jpn J Cancer Res 93, 842-847.

Nilsson, I., Ljungh, Å., Aleljung, P. \& Wadström, T. (1997). Immunoblot assay for serodiagnosis of Helicobacter pylori infections. J Clin Microbiol 35, 427-432.

Nilsson, H.-O., Taneera, J., Castedal, M., Glatz, E., Olsson, R. \& Wadström, T. (2000a). Identification of Helicobacter pylori and other Helicobacter species by PCR, hybridization, and partial DNA sequencing in human liver samples from patients with primary sclerosing cholangitis or primary biliary cirrhosis. J Clin Microbiol 38, 1072-1076.

Nilsson, I., Lindgren, S., Eriksson, S. \& Wadström, T. (2000b). Serum antibodies to Helicobacter hepaticus and Helicobacter pylori in patients with chronic liver disease. Gut 46, 410-414.

Nilsson, H.-O., Mulchandani, R., Tranberg, K.-G., Stenram, U. \& Wadström, T. (2001). Helicobacter species identified in liver from patients with cholangiocarcinoma and hepatocellular carcinoma. Gastroenterology 120, 323-324.
Nilsson, H.-O., Stenram, U., Ihse, I. \& Wadström, T. (2002). Re: Helicobacter pylori seropositivity as a risk factor for pancreatic cancer. J Natl Cancer Inst 94, 632-633.

Roe, I. H., Kim, J. T., Lee, H. S., Lee, J. H. (1999). Detection of Helicobacter DNA in bile from bile duct diseases. J Korean Med Sci 14, $182-186$

Soltesz, V., Zeeberg, B. \& Wadström, T. (1992). Optimal survival of Helicobacter pylori under various transport conditions. J Clin Microbiol 30, 1453-1456.

Sutton, I. \& Neuberger, J. (2002). Primary biliary cirrhosis: seeking the silent partner of autoimmunity. Gut 50, 743-746.

Verbaan, H., Hoffmann, G., Lindgren, S., Nilsson, S., Widell, A. \& Eriksson, S. (1998). Long-term outcome of chronic hepatitis C infection in a low-prevalence area. Scand J Gastroenterol 33, 650-655.

Wadström, T., Ljungh, Å. \& Willén, R. (2001). Primary biliary cirrhosis and primary sclerosing cholangitis are of infectious origin! Gut 49, 454.

Ward, J. M., Benveniste, R. E., Fox, C. H., Battles, J. K., Gonda, M. A. \& Tully, J. G. (1996). Autoimmunity in chronic active Helicobacter hepatitis of mice. Serum antibodies and expression of heat shock protein 70 in liver. Am J Pathol 148, 509-517. 